\title{
Carbon Credits on Private Lands in British Columbia
}

\author{
Balbinder Deo, Han Donker, Michael Schulz
}

School of Business, University of Northern British Columbia, Prince George, Canada.

Email: donker@unbc.ca

Received August 16 $6^{\text {th }}, 2012$; revised September 20 $0^{\text {th }}$ 2012; accepted October $7^{\text {th }}, 2012$

\begin{abstract}
This study assesses the production potential of carbon credits on private land in Central British Columbia through pine forest plantation projects. This study identifies the quality characteristics for determining the quality standards for carbon credits, and then uses those quality characteristics along with the standardized procedure to assess the quality and quantity of carbon that can be fixed in forest projects and thus be registered on the carbon exchange as carbon credits or offsets for trading on per hectare basis. Using the Table Interpolation Program for Stand Yields (TIPSY) which is a tree growth simulation model, sites of various productivities (Site Index values of 24, 21, 18, and 12) in the PGTSA, BC, Canada were modeled to generate data related to stands of trees for timber volume, lumber production, and subsequent carbon credit/offsets generation. Using data and information from the industry and the Government of British Columbia Ministry of Forests and Range (BCMoFR), cost-related data for forest stand establishment and maintenance was generated. Using market pricing methodology for offsets in the "over the counter" (OTC) market, Internal Rate of Return (IRR) calculations were performed. The results of the study indicated that rate of return varied in the range of $0.27 \%$ to $0.51 \%$ over a period of 57 to 100 years. Only three out of sixteen modeled production scenarios indicated positive rates of return. Overall, the study concluded that sequestering carbon in forest projects on private land in PGSTA, BC is not restricted by any production quality criterion, but that it is financially unviable given the current costing and carbon offset pricing regimes.
\end{abstract}

Keywords: Production Potential; Forests; Carbon Credits; Private Land

\section{Introduction}

A carbon credit is created when one metric tonne of carbon dioxide or its equivalent is prevented from entering the atmosphere or neutralized from the atmosphere. The underlying basis of measurement of carbon credits is the amount of carbon that is prevented and or neutralized by taking on the projects designed to reduce the emissions of, or provide for the sequestration of Carbon Dioxide $\left(\mathrm{CO}_{2}\right)$ from the atmosphere versus the status quo. The amount of carbon prevented or neutralized is certified and turned into financial instruments called carbon credits that are purchased, sold or transferred in a carbon market in terms of units of metric tonnes of carbon dioxide equivalent $\left(\mathrm{MtCO}_{2} \mathrm{e}\right)$.

The major chunk of the carbon credit market consists of projects based on energy efficiency, renewable energy, methane destruction, and forestry-based land projects [1]. It is a new commodity that has no intrinsic value of its own but whose value depends entirely on the stability of government policy and the green house gases (GHG) emissions program that helps create it, or on the goodwill of companies that choose to buy it in order to reduce or offset their carbon footprints [2]. In available literature and in the carbon markets, terms like carbon credits and carbon offsets are often used interchangeably.

Increasing concern about climate change led to the formation of the United Nations Framework Convention on Climate Change (UNFCCC) in 1992. The 1997 Kyoto Protocol was ratified with a specific mandate to develop strategies aimed at both reducing emissions and potential re-capturing of greenhouse gases from the atmosphere. This resulted in an international legally binding agreement in which 180 industrialized countries agreed to reduce their collective greenhouse gas emissions below their 1990 emissions levels by 2012 [1].

The Kyoto protocol objectives related to global warming cannot be accomplished only through control measures that physically reduce the volume of emissions. Absorption/sequestration mechanisms that remove the gases from the atmosphere are also necessary. A consistent measurement is required to systematically track and communicate emissions volumes, and with roughly $72 \%$ of GHGs being made up of Carbon Dioxide $\left(\mathrm{CO}_{2}\right)$, carbon is used as the international standard of measurement in terms of Metric Tonne Carbon Dioxide Equivalent $\left(\mathrm{MtCO}_{2} \mathrm{e}\right)$. An $\mathrm{MtCO}_{2} \mathrm{e}$ is equal to 1000 kilograms of 
$\mathrm{CO}_{2}$ emissions, and the actual carbon content in it is equal to 272.5 kilograms, which is the molecular weight of the Carbon component relative to the Oxygen component $\left(\mathrm{MtCO}_{2} \mathrm{e} . \mathrm{com}, 2008\right)$. However, the international measurement unit for carbon is the mega gram (Mg). An $\mathrm{Mg}$ is equivalent to 1000 kilograms or one tonne of Carbon and it is equal to $3.6667 \mathrm{MtCO}_{2} \mathrm{e}$. In the context of emissions measurements, terms such as $\mathrm{CO}_{2}$ emissions, carbon emissions, carbon dioxide emissions and greenhouse gas (GHG) emissions are all used synonymously.

With Kyoto serving as a regulatory mechanism for monitoring and reducing emissions, the countries signatory to the protocol are legally bound to reduce their emissions output to meet their global environmental responsibility. In this context, the form and amount of "carbon" that a country could fix and hold back in storage began to have a value. Through either regulated or voluntary mechanisms, countries pursuing the reduction of emissions need to do so even if it means at a cost. Thus, the question began to be asked: "What is the value of an $\mathrm{MtCO}_{2} \mathrm{e}$ ?" The answer to this question is found through the establishment and implementation of a "Carbon Market” that traded carbon credits and offsets.

Carbon credits are offered for sale in two markets: the large compliance market and the small voluntary market. The large compliance market trades close to 4146 million $\mathrm{MtCO}_{2} \mathrm{e}$ of offsets with a value of $\$ 117.6$ billion US, and the smaller voluntary market trades 123 million $\mathrm{MtCO}_{2} \mathrm{e}$ of offsets with an approximate value of $\$ 0.704$ billion US [3]. Offsets traded in the compliance market are done so through standards established under the Kyoto agreement. International rules and procedures for measuring and trading carbon are developed by the United Nations Framework Convention on Climate Change (UNFCCC) and its partner the International Panel on Climate Change (IPPC) [3]. The Clean Development Mechanism (CDM) as defined in Article 12 of the Kyoto agreement allows for industrialized countries to acquire Certified Emission Reductions (CERs) from project activities related to renewable energy, energy efficiency, and land use and forestry related activities [4].

The requirements to service offset customers, has resulted in the rapid evolution of the voluntary carbon market. At the broadest level, the voluntary carbon markets themselves can be divided into two main segments: the voluntary but legally binding cap-and-trade system that is known as the Chicago Climate Exchange (CCX), and the other non-binding, over-the-counter (OTC) offset market.

It is the existence of the voluntary market, and the demand for offsets within the voluntary market, particularly the OTC market, that provide an opportunity for private landowners. Forest based carbon sequestration projects are undertakings through which atmospheric Carbon Dioxide $\left(\mathrm{CO}_{2}\right)$ is transferred into long-lived carbon pools (trees/wood products where it is kept stored securely so that it is not immediately re-emitted back into the atmosphere) that are well recognized as an offset source [5].

There is substantial literature on carbon markets related to size, trends, and pricing perspectives. The market for carbon offsets resulting from project based transacttions is growing at an exponential rate. Pacific Carbon Trust [6] projects that the carbon market will be an industry worth $\$ 3.1$ trillion US by the year 2020. While much of the growth in volume has been experienced in the regulated markets governed by Kyoto's Clean Development Mechanisms (CDMs), the growth rate of the voluntary OTC market has actually outpaced the regulated market. For the year ending 2008, the OTC voluntary market grew by $84 \%$ compared to the regulated markets growth of $46 \%$ [1].

Within the regulated market, forest land based offsets have played only a minimal role and accounted for only $1 \%-2 \%$ of the credits exchanged. This is in stark contrast to the OTC market, in which forestry projects accounted for $18 \%$ of the market share in 2008 , and have ranked in the top four sectors of market contribution for the years 2006-2008 [1,7]. Research indicates that a high percentage of offset purchasers (75\%) have a positive view of forest carbon, and may be willing to pay premiums for projects that meet their criterion $[1,8]$.

Afforestation and reforestation (A/R) are the two primary types of forest projects that constitute a planned set of forestry management or land-use change activities designed to remove, reduce or prevent carbon dioxide emissions by conserving and/or increasing forest carbon stocks. Afforestation is defined as the planting of trees on land that historically has not supported forests; reforestation is the replanting of forests on land that was previously forested [9]. Through participation in afforestation and reforestation projects, landowners have the ability to generate carbon credits that they can make available for sale in markets. Many consider forestry projects as the most "classical" type of offset project [8], set apart from other offset projects in that they create a tangible commodity - wood fiber-and that too through bio-sequestration or extracting $\mathrm{CO}_{2}$ from the atmosphere in a natural way [2]. Hamilton et al. [1] identified offsets generated from forestry projects as not only the most heavily transacted type on the OTC market, but also commanding premium for projects associated with afforestation and reforestation activities.

Private land in central British Columbia offers a unique opportunity for the creation of forest plantation based carbon credits. However, in this study, the focus is on private land that falls specifically within the PG Timber 
Supply Area (PGTSA). The PGTSA is located in northcentral British Columbia and covers approximately 7.97 million hectares of the Northern Interior Forest Region. PGTSA spans an area ranging from the Blackwater River in the south to the headwaters of the Skeena River in the north, and covers a diverse landscape of mountains and interior plateau (MoFR, 2010). Mostly private land holdings are concentrated in close proximity to the urban areas of Prince George, Vanderhoof, and Fort St. James, and along the highway corridors that connect them. Private lands account for 321,940 hectares of land (approximately $4 \%$ of the PGTSA area). This distribution of private land, in both volume and spatial distribution, is consistent with the rest of the province (94\% of British Columbia is publicly owned).

The quality and subsequent value of carbon credits is influenced by the sophistication of the carbon standards applied to a project, and the validation process. Understanding which standard is most appropriate for forestry applications is important for maximizing the future value of carbon credits. Therefore, the precise objectives of this study are:

- Identification of the quality characteristics that need to be considered for the generation of carbon credits.

- Assessment of the amount of carbon that can be sequestered and made available for sale in the market in different climatic conditions on private land in central British Columbia, Canada.

This paper is divided into five sections. Section one contains the introduction. Section two discusses the literature and section three deals with the research methodology. The literature review section is helpful in identifying the quality characteristics important for the production of carbon credits. Section four deals with the BioGeoClimatic Ecosystem Classification (BEC) related conceptual framework that is used to identify BioGeo zones and sub-zones in which private lands fall. The BioGeo Zones with the same Site Index (SI) for pine forests is shown in the stratum based on the same SI, and then the standardized procedure to assess carbon credits is discussed. In section four, data relating to private lands for each SI-based stratum is analyzed and discussed. The conclusions based on the analysis and discussion section are provided in section five along with the future research directions in this area of study.

\section{Literature Review}

This section reviews the theoretical as well as empirical literature regarding the generation of carbon credits on private forestlands. Though there is a plethora of literature available related to carbon credit/offset establishment and trading, most of it is less than ten years old, as the "carbon industry" came about as a result of the Kyoto agreement in 1997.
The province of BC (British Columbia, Canada) is in the process of developing a forest offset protocol to define acceptable offsets that could also be considered by the BC Government. However, the scope of this paper is related to private land, and therefore, the viability of such projects will not be limited to the British Columbia government standard, as the credits generated could also be available for sale on the OTC market. The differences in the standards for the markets in which they are sold have an impact on the value of the credit. For example, those credits that follow higher, more stringent standards and are eligible for the compliance market fetch higher values. In addition, there are also potential differences in the actual volume calculations that determine the amount of credit produced.

Some common characteristics that need to be considered for carbon assessment are discussed in much of the available literature on carbon standards. The most common characteristics discussed in most of the papers are additionality, permanence, leakage, transparency, and registration. Each of these factors are discussed and evaluated in the following paragraphs.

The basis of carbon credits related projects must be transparently established to provide project credibility. Additionality can be expressed as the requirement for a project to produce results such as emission reductions or removals that should be in addition to those that would have occurred even in the absence of the project [10]. The Kyoto Protocol outlines this concept as a requirement for plans to reduce GHGs over and above the Business as Usual (BAU) case scenario.

In order to measure additionality in quantitative terms, it is necessary to establish a baseline or reference point against which a project's carbon storage potential can be measured. It is the difference between the baseline volume and the volume of carbon sequestered as a result of the project that becomes available for sale as a credit.

Forest projects commonly use two methodologies"base year" and "business as usual" (BAU)—for establishing baselines. As per Beane et al. [10], the Business as Usual (BAU) methodology compares a project's carbon stocks to the estimated/modeled amount that would have naturally occurred in the absence of the project being undertaken. The base year approach pegs a starting point and compares the actual measurements of a project's carbon stocks year over year. The base year approach does not consider the outcome of not undertaking the project, and this leads to the questions such as, "Did the project yield any real changes in sequestration levels?" On the other hand, the BAU approach is challenged due to the use of hypothetical projections of sequestration rates made many years into future that may not match the actual sequestration rates to be observed in future [10]. 
For the purposes of afforestation and reforestation activities, the base year approach is more suitable as it involves operations such site preparation, brush clearing or burning prior to planting [2]. In this kind of project, the additional carbon stored (Addionality) is evaluated using four tests [9]:

1) Legal and Regulatory Test of Additionality (Regulatory urplus): A project that is implemented to fulfill official policies, regulations, or industry standards, cannot be considered additional;

2) Investment Test: The project would have a lower than acceptable rate of return without revenue from the sale of carbon credits/offsets. In other words, the revenue from the carbon credits/offsets must be a decisive reason for implementing a project;

3) Barrier Test: The project succeeds in overcoming significant non-financial barriers such as local resistance, lack of know-how, institutional barriers, etc., and if the business-as-usual alternative does not face these barriers, then it is not considered additional;

4) Common Practice Test: The project that employs very commonly used technologies might not be additional because it is likely that the carbon credit/offset benefits do not play a decisive role in making the project viable.

The forest carbon project's ability to pass each of these tests gives credence to a viable and respectable carbon credit/offset project type.

Rotherham [2] described permanence as the removal of a GHG molecule permanently from the atmosphere, while Beane et al. [10] described it as the removal of $\mathrm{CO}_{2}$ from the atmosphere for a time period at least as long as the emitted gas that is being sequestered is contributing to climate change. Permanence is considered one of the major concerns in any forestry related project [10-13] because of the inherent risks and uncertainties associated with natural threats such as pests and diseases, climate change, anthropogenic risks related to encroachment, land management as well as political risks such as weak property rights and their non-enforcement, economic and financial vulnerabilities such as exchange rate fluctuations, changing opportunity costs, and institutional risks $[13,14]$ that may span over long periods of time.

Marland et al. [12] provided a commonly accepted format of a "Credit Withholding" system, whereby a percentage of the carbon benefits from each project entered into the voluntary carbon offset program is withheld and made unavailable for sale. This is designed to make up for any natural damage that could occur to the project in future years. This methodology can be practically applied to $\mathrm{A} / \mathrm{R}$ projects where the project proponent would not recognize the entire volume of carbon being sequestered, and would always have to "maintain some amount in a bank”.
The International Panel on Climate Change (IPCC) defined "leakage" as the "unanticipated decrease or increase in GHG benefits outside of the project's accounting boundary, as a result of the project related activities”. In the forest management context, leakage can be viewed as the increase in harvest in other areas of forest to balance any decrease in harvest on a forest land that is being managed as a forest carbon project [2]. Deforestation leakage is similar to a "shell game", occurring when an afforestation or reforestation offset project being conducted on one parcel of land results in the deforestation of another parcel, i.e. one landowner converts agriculture land to forest land to gain the benefit of the offsets, while at the same time, another converts forest land to agricultural uses. From a private land perspective, it is imperative that owners recognize this requirement for all parcels of land that they are going to include in forest carbon projects, as it will potentially limit their ability to harvest volumes of mature timber.

Sustainable harvest rates, commonly referred to as annual allowable cuts (AAC) must clearly differentiate between a project that is part of normal forest management project and a project that is a forest carbon credit/ offset project, with the latter not contributing additional volume of wood for harvesting. It is proposed that a forest carbon project on private lands does not have to address leakage issues, but it is anticipated that any leakage from properties participating in the forest carbon project should be the responsibility of the landowner.

These are the positive ancillary environmental, social, and economic outcomes that result from an offset project [10]. These benefits set the context in which carbon projects are undertaken in a more "holistic framework". Forest projects often garner support ahead of other offset projects because of the additional benefits they provide and these are often associated with wildlife habitat, clean water, recreation, biodiversity, and eco-tourism [1]. In terms of potential economic benefits, forest projects are also known to attract a premium for the offsets they generate. The positive association of a "green, healthy forests" with a "green, healthy environment" results in many companies choosing to purchase forest carbon credits/ offsets for purposes of branding and also as an evidence of their corporate social and environment responsibility.

The compilation and integration of the concepts related to additionality, permanence, leakage, and co-benefits are ultimately defined as Forest Carbon Standards. Standards in the regulated market have existed since the ratification of the Kyoto Protocol, and are viewed by many as complex, bureaucratic and cumbersome. Hamilton et al. [1] also revealed different standards based on types of projects, the methodologies they employ, and their start dates. In 2007, the quality of offsets was also challenged in the media, and in order to maintain credibility, many 
suppliers started to pursue a standardized accreditation process too. It is important that forest project proponents consider and understand different standards and their unique offerings and requirements before they undertake any work. This would enable the fulfillment of the key standard requirements for registering and reporting offsets.

Carbon credit accounting registries are designed specifically to track the volume of carbon being generated and traded, with serial numbers being attached to each block of offsets. This component of a standard allows for transparency related to each and every individual offset that flows within the carbon market.

Forest carbon stock models have been devised in order to estimate and account for the volumes of carbon being generated through forests plantation, growth and harvesting under different regimes. These models accurately determine the amount of carbon that is being sequestered from both a temporal and quantitative perspective. The data and information thus generated is critical in the decision making process for private landowners to pursue forest projects as future revenue streams are dependent on the accurate assessment of volumes of credit/offsets that could be available for sale [15].

In general, forest carbon modeling is undertaken in a series of logical steps [3]. It is important to note that not all standards are acceptable in all models, and that prior to establishing a project, proponents need to ensure that the model that they are proposing to use should be one that accepts the standards that they are working under and provides a sufficient level of detail and accuracy. Most commonly accepted models within Canada and more specifically, British Columbia, include CBM-CFS3 (Carbon Budget Model-Canadian Forest Service Version 3), and FORECAST [16].

\section{Identification of Biogeoclimatic Zones}

British Columbia uses a forest classification system called the Biogeoclimatic Ecosystem Classification (BEC). BEC is a hierarchical system that combines climatic, vegetation, and site characteristics to organize ecological information and management experience [17]. The BEC system divides the land base into Biogeoclimatic Zones (BioGeo Zones) and further into sub-zones that are characterized by “zonal sites”. Zonal sites can be described as representative sites within the subzone, and used to provide a proxy for potential growth rates of planted species on a particular site.

The system of BioGeo Zones is overlaid on top of the land considered for the carbon sequestering project and the zonal site index is then determined using the Site Index Estimates by Site Series for a specific species in the BioGeo Zone or subzone. The growth potential of a site is represented by the Site Index (SI50) that specifi- cally means height of a tree measured in metres (m), of a particular species at the age of 50 years.

With inputs generated based on the forest land related BioGeo Zone Site Index (SI50), wood volume could be determined in terms of board feet sawn lumber using the Table Interpolation Program for Stand Yields (TIPSY). The basic unit of measurement used in the industry is the sawn lumber in terms of board feet, which can be employed to determine the actual carbon sequestered as a function of board feet using the TIPSY Lumber and Chips Table. Based on a conversion table of oven-dry wood densities (carbon content being 50\% of oven-dry wood), the volume of sawn lumber can be converted into the volume of carbon sequestered using a series of calculations.

An important point to note is that the growth rates of trees and the subsequent sequestration of carbon is not constant over the growth cycle of such projects. These projects would initially not generate any available harvestable volume that can be converted into lumber for the first few years of the project. Over time, the growth rates and the available sequestered carbon grow exponentially until they reach culmination age. The uneven rate of sequestration has implications on the amount of volume of carbon credits/offsets available for sale, and the cash flows arising from sales as well.

Using the Kollmus et al. [9] criterion for additionality, private land in British Columbia can be found to fulfill all the required criteria, i.e. the Legal as well as Regulatory Additionality Test, Investment Test, Barrier Test and Common Practice Test. Most of the private land is owned in "fee simple", a form of absolute ownership, wherein the owner has the right to use it in any way he or she chooses. As such, owners are not required to establish crops of any kind or manage the land base in accordance with any regulated standard. This important attribute allows for the passing of the Legal and Regulatory Additionality Test in providing that the establishment of a forest crop can be beyond what is legislated.

The Investment Test is examined in the context that establishing forest crops for the purpose of generating forest products (lumber and chips) is not financially viable because of the longer rotation ages (60 - 80 years) on many lower productivity interior forest sites. Landowners would be required to spend money to establish crops with limited potential to recognize the benefits within their lifetime. The fact that forest crops have always yielded a lump sum payment at the time of harvest as opposed to continued cash flows has also been a reason why activities have not been pursued. Should the additional revenue stream generated from carbon offsets be great enough to kick-start the project, then it could be viewed as a decisive reason to implement it, and the project would thus pass the Investment Test as well. 
The Barrier Test is fulfilled by the land owner's requirement to overcome his/her lack of know-how and become well versed in the practices of crop establishment and management, as well as the carbon market. Although the establishment of forest crops does not employ any new technologies, the Common Practice Test is reviewed in the light of a landowner using a common practice in a new way. Landowners have historically left their land fallow after removing the forest cover, and those lands that have been converted to agricultural use have limited productivities (for agricultural crop purposes). The establishment of forest crops on marginal agriculture lands or denuded forestlands is therefore a clear example of a practice that fulfills the Common Practice Test.

The concepts of permanence and leakage are both well addressed by the "fee simple" ownership structure of the private land. With absolute control over all of the activeties that take place on the land base, the owner can control the processes associated with crop establishment and management. Specifically, the owner can withhold a percentage of the offsets made available for sale, thereby ensuring that permanence is maintained, should a portion of the stand succumb to a catastrophic event. Furthermore, with control of the land base, the owner can ensure that the project does not result in any additional activities that release carbon.

With respect to co-benefits, it is found that the establishment of forest crops on private lands generates only positive outcomes. Products and benefits such as wildlife habitat, clean water, recreation and biodiversity are all achieved by planting trees. Additionally, with much of the private land lying in close proximity to urban areas and highway corridors, the aesthetics of the landscape can be improved by planting trees as opposed to keeping the land raw and without forest cover.

For the purposes of this study, the system of BioGeo Zones and sub-zones as per BEC is overlaid on top of private lands to determine the variability and distribution of the different classifications and their representation within the private land base.

Fifteen different sub-zones are identified within the private lands and labeled ICHvk2, ICHwk3, SBPSmc, SBSdk, SBSdw1, SBSdw2, SBSdw3, SBSmc2, SBSmc3, SBSmh, SBSmk1, SBSmw, SBSvk, SBSwk1, and SBSwk3. A zonal site index using the Site Index Estimates by Site Series for Coniferous Tree Species in British Columbia is allocated to each of these subzones. The growth potential of a site is represented by a Site Index (SI50) that specifically means height of a tree measured in metres (m) of a particular species at the age of 50 years. In the PGTSA, four different site indices were determined for pine, with values of 12, 18, 21 and 24. In other words, BioGeo Subzones are stratified into four strata based on tree height in metres in a 50-year time frame.
Table 1 shows the private land distribution in 12 BioGeo subzones that have private land, the amount of land in terms of hectares in each subzone, and the site index for the zonal site within the sub-zone.

Forest management strategies are often tied to BioGeo subzones. The different strategies are based primarily on the difficulty of establishing and maintaining a forest crop on the land base, with those subzones that provide greater challenges commonly associated with increased costs. The increased costs often result from the requirements for either higher percentage of standard activities or additional activities in the form of mechanical site preparation (MSP), brushing and weeding, fill planting and surveying.

The steps involved in the calculations are as follows:

Step 1: Estimation of sawn lumber in terms of board feet: The quantity of sawn lumber in terms of board feet is the function of the Site Index (50). Higher the value of the site index, higher would be the amount of board feet of lumber that could be recovered. For example, the Site Index (50) with a value of 24 metres will provide more recoverable wood in terms of board feet as compared to Site Index (50) with a value of 21 metres or less. The quantity of board feet per hectare for a given value of Site Index (50) can be directly taken from the TIPSY Lumber and Chips Table.

Step 2: Calculation of pine wood volume, weight, and weight of carbon sequestered: It has been determined in wood industry that one board feet of oven-dry lumber is equivalent to 0.002359722 cubic metre of wood volume. A cubic metre of oven dry pine wood lumber is equivalent to $400 \mathrm{~kg}$ by weight. A tonne of oven dry pine wood lumber/cubic metre is equivalent to 0.5 tonnes of carbon /cubic metre. Therefore,

$$
\text { Csq }=(X \cdot 0.002359722 \cdot 400 \cdot 0.5) / 1000
$$

where, Csq is tonnes of carbon sequestered/hectare and $\mathrm{X}$ is quantity of oven dry board ft available at given age/ hectare

This formula can be used to calculate the quantity of carbon sequestered at culmination age by finding the value of $\mathrm{X}$ at the culmination age.

Table 1. Private land area BioGeo subzone stratification based on site index.

\begin{tabular}{ccc}
\hline BioGeo Subzone & $\begin{array}{c}\text { Area } \\
\text { (hectares) }\end{array}$ & $\begin{array}{c}\text { Zonal Site } \\
\text { Index }\left(\mathrm{SI}_{50}\right)\end{array}$ \\
\hline $\begin{array}{c}\text { ICHvk2, SBSdw1 } \\
\text { ICHwk3, SBSdw2, SBSmh, } \\
\text { SBSmk1, SBSmw }\end{array}$ & 15,712 & 24 \\
$\begin{array}{c}\text { SBSdk, SBSdw3, SBSmc2, } \\
\text { SBSmc3 }\end{array}$ & 107,280 & 21 \\
SBPSmc & 198,914 & 18 \\
\hline
\end{tabular}


Step 3. Calculation for metric tonnes of carbon dioxide equivalent sequestered: One tonne of carbon fixed in trees is the result of 3.67 tonnes of Carbon Dioxide sequestered. The factor 3.67 is based on the chemical composition of Carbon Dioxide. Therefore,

$$
\mathrm{MtCO}_{2} \mathrm{e}=\mathrm{Csq} \cdot 3.67
$$

where $\mathrm{MtCO}_{2} \mathrm{e}$ is tonnes of Carbon Dioxide equivalent sequestered/hectare

Tonnes of Carbon Dioxide equivalent sequestered at the culmination age can be calculated using the formula in Equation (2).

Step 4. Metric tonnes of carbon dioxide equivalent available for sale calculations: The reviewed literature related to carbon additionality and permanence recommends that $20 \%$ of the carbon credits generated must be withheld for assuring permanence. Therefore,

$$
\mathrm{MtCO}_{2} \mathrm{e} \text { available for sale/hectare }=\mathrm{MtCO}_{2} \mathrm{e} \cdot 0.8
$$

Tonnes of carbon dioxide equivalent available for sale at the culmination age can be calculated using Equation (3). To calculate the average meotric tonnes of Carbon Dioxide equivalent available for sale at the culmination age, the formula in Equation (3) can be modified as:

Average $\mathrm{MtCO}_{2} \mathrm{e}$ available for sale (at age "n") = $\left(\mathrm{MtCO}_{2} \mathrm{e}\right.$ available for sale (at age " $\mathrm{n}$ ”)/hectare) $/ \mathrm{n}$ where " $n$ " is the Culmination age.

\section{Empirical Results}

The 321,940 hectares (ha.) of private lands in the data set are composed of 12 unique BioGeo subzone-variants. The Sub-Boreal Pine-Spruce moist-cold (SBPSmc) is the least represented subzone with only 34 ha., and the Sub-Boreal Spruce dry-warm-3 (SBSdw3) is the most represented with 127,274 ha. Zonal site indices across the subzones are represented by four SI50 measurements12, 18, 21 and 24 for pine. The lower the site index, the lower the productivity of the site. These four site indices are modeled for growth potential. Pine was chosen as the species to model because of its higher site indices as compared to spruce on the same site and subsequent higher growth rates. Table 2 summarizes the distribution of subzones and the associated site indices. The dominant site index for pine is found to be SI50-18.

For each subzone, both Canfor and the BC Ministry of Forests and Range (MoFR) provided cost information regarding the establishment and maintenance of forest stands. Costs are recorded on a "per hectare" basis and for an individual subzone. While costs between the two sources vary, there is general consistency in recognition of the higher and lower cost subzones. In order to get a representative cost associated with a Site Index (growth potential), a weighted average of cost/subzone repre sented by each of the four site indices is generated. Table 2 also summarizes the distribution of subzones and asso-
Table 2. Private land area BioGeo subzones with site index

\begin{tabular}{|c|c|c|c|c|}
\hline $\begin{array}{l}\text { BioGeo } \\
\text { Subzone }\end{array}$ & $\begin{array}{c}\text { Area } \\
\text { (hectares) }\end{array}$ & $\begin{array}{c}\text { Zonal Site } \\
\left.\text { Index (SI }{ }_{50}\right)\end{array}$ & $\begin{array}{c}\text { \$Cost } \\
\text { (Canfor) }\end{array}$ & $\begin{array}{c}\text { \$ Cost } \\
\text { (MoFR) }\end{array}$ \\
\hline $\begin{array}{l}\text { ICHvk2 } \\
\text { SBSdw1 }\end{array}$ & 15,712 & 24 & 1472.12 & 972.48 \\
\hline $\begin{array}{l}\text { ICHwk3 } \\
\text { SBSdw2 } \\
\text { SBSmh, } \\
\text { SBSmk1 } \\
\text { SBSmw }\end{array}$ & 107,280 & 21 & 807.92 & 1167.66 \\
\hline $\begin{array}{c}\text { SBSdk } \\
\text { SBSdw3 } \\
\text { SBSmc2 } \\
\text { SBSmc3 }\end{array}$ & 198,914 & 18 & 663.01 & 960.15 \\
\hline SBPSmc & 34 & 12 & 761.50 & 1081.00 \\
\hline
\end{tabular}
(50), and cost/hectare.

ciated Canfor and MoFR costs, and shows the average cost numbers associated with each stratum based on site index value.

In order to understand the potential volume of carbon being sequestered and the potential volume of offsets being generated, each of the four site indices for pine was modeled using TIPSY.

TIPSY is a provincially recognized growth and yield program that uses site-specific inputs (site index, species, planting densities, etc.) to generate site-specific outputs in terms of volume yields of logs and lumber. It also interpolates information and projects mean annual increment and culmination age. Mean annual increment (MAI) is the "mean volume" by which a stand is growing. It changes over time-starting slowly, followed by a rapid increase, then plateauing and falling off. The age at which a stand reaches maximum mean annual increment is known as culmination age. Culmination age is the target rotation age (or the age when the stand is harvested) of managed stands because it maximizes the log volume production, and for the purposes of generating offsets, associated with sequestered carbon. MAI and culmination age are site- and species-specific. Sites with higher SI50 have younger culmination ages and higher MAIs, that is to say, the sites establish more volume at a quicker rate. Table 3 summarizes the maximum MAIs and culmination ages for pine site indices found on private lands. Pine SI50-24 has the highest MAI, i.e. $7.90 \mathrm{~m}^{3} / \mathrm{ha} /$ year, and the shortest culmination age of 57 years.

The TIPSY Lumber and Chips Table was used to determine the volume of lumber that could be generated on a per hectare basis at any age up to the culmination age. For the first years following establishment, even though the stand is growing and adding biomass, the volume of logs available to make lumber is "zero". As the volume of lumber available to be produced is zero, the volume of offsets available for sale is also "zero". This is due to the fact that the log has to grow to a sufficient size in order 
to be milled. For the purposes of this analysis, common merchantability standards were applied in the TIPSY model $(10 \mathrm{~cm}$ top diameter of the log and $12.5 \mathrm{~cm}$ butt diameter). With these standards applied, the earliest a site was able to generate any offsets in the form of merchantable lumber was age 13 (SI50-24). This time period got increased to 27 years for SI50-12. Also, it is evident that lumber recovery is a function of log size, and a log has to achieve a certain threshold size before it allows another board to be extracted from it. This phenomenon results in the volume of lumber, and subsequent carbon sequestered following a stepped curve approach.

The volume of lumber board feet per hectare (bf/ha.) was converted back into "solid wood" volume $\left(\mathrm{m}^{3} / \mathrm{ha}\right.$.) using a constant multiplier of $1 \mathrm{bf}=0.00235973722 \mathrm{~m}^{3}$. The carbon content of wood is commonly accepted as $50 \%$ carbon, and the oven dry weight of pine is 400 $\mathrm{kgs} / \mathrm{m}^{3}$. Therefore, each cubic metre of pine boards contains about $200 \mathrm{~kg}$ of carbon.

The average sequestration rate for each site index is determined by dividing the total carbon sequestered in boards at culmination age and then dividing it by the culmination age. Though this average method of calculation does not reflect the actual rates at which carbon is sequestered, it could be used to create a more even stream of cash flows over the life of the forest carbon project. By using an average method, a revenue stream could be generated immediately after the project is implemented as opposed to waiting until the site produces lumber of a merchantable size.

Table 4 provides the final amount and the average sequestration rate at culmination age for the four site indices examined for this study.
Pricing of forest carbon offsets is both highly variable and volatile. The variability of pricing is a function of the markets that the offset is sold in, the standards under which the project has been developed, and the inherent attractiveness of the project to the purchaser. For the purposes of this analysis, the Over-the-Counter (OTC) market was selected as the basis for establishing price. Unlike the regulated markets and the Chicago Climate Exchange (CCX), the OTC market provides a set of standards that is readily achievable without the need to have high levels of expertise. The OTC market allows for projects of minimal size to be combined or aggregated, thereby allowing for developments that may not have been recognized in any one of the other markets. Finally, the OTC market brings together a diverse set of both offset producers and offset customers in a forum that allows for the customers to source out projects that they feel best suited to their preferences.

The volatility of the market is explained by the fact that carbon offsets are a commodity, and as such, subject to all of the market pressures associated with any other commodity. In a market where many types of offsets are available, differentiation is the key to attaining higher demand/price. To date, A/R type projects have demanded a premium, primarily because of their positive association with co-benefits and because they generate a commodity (fiber) that also has a residual value. Historical price data for A/R projects is summarized in Table 5 .

For the purpose of IRR calculations, the four-year numeric average value of $\$ 7.65 \mathrm{Cdn} / \mathrm{MtCO}_{2} \mathrm{e}$ is used. Thus, using the productivity, cost, and pricing information, IRR calculations were performed on the dataset. Internal Rates of Return were determined for both Canfor and MoFR cost

Table 3. Culmination ages and Mean Annual Increments (MAIs) for pine on various site indices.

\begin{tabular}{|c|c|c|c|c|}
\hline BioGeo Subzone & Area (hectares) & Zonal Site Index $\left(\mathrm{SI}_{50}\right)$ & Culmination Age (years) & MAI $\left(\mathrm{m}^{3} / \mathbf{y r} / \mathbf{h a}\right)$ \\
\hline ICHvk2 SBSdw1 & 15,712 & 24 & 57 & 7.90 \\
\hline $\begin{array}{l}\text { ICHwk3 SBSdw2 SBSmh } \\
\text { SBSmk1 SBSmw }\end{array}$ & 107,280 & 21 & 58 & 6.21 \\
\hline $\begin{array}{c}\text { SBSdk SBSdw3 SBSmc2 } \\
\text { SBSmc3 }\end{array}$ & 198,914 & 18 & 75 & 4.57 \\
\hline SBPSmc & 34 & 12 & 110 & 2.02 \\
\hline
\end{tabular}

Table 4. Total final and average sequestration rate $\left(\mathrm{MtCO}_{2} \mathrm{e} / \mathrm{yr}\right.$.) at culmination age.

\begin{tabular}{ccccc}
\hline $\begin{array}{c}\text { Zonal Site Index } \\
\left(\mathbf{S I}_{\mathbf{5 0}}\right)\end{array}$ & Culmination Age (years) & $\begin{array}{c}\text { Bone Dry Carbon } \\
\text { Sequestered (tonnes) }\end{array}$ & $\begin{array}{c}\text { Final } \mathbf{M t C O}_{\mathbf{2}} \mathbf{e} \\
\text { (tonnes) }\end{array}$ & $\begin{array}{c}\text { Average MtCO } \mathbf{2} / \text { /year } \\
\text { (tonnes) }\end{array}$ \\
\hline 24 & 57 & 49.9 & 183.1 & 3.21 \\
21 & 58 & 37.9 & 131.5 & 2.27 \\
18 & 75 & 35.7 & 123.9 & 1.65 \\
12 & 110 & 20.8 & 72.2 & 0.66 \\
\hline
\end{tabular}


estimates using actual and average sequestered $\mathrm{MtCO}_{2} \mathrm{e}$. The actual calculation reflects the volume of carbon offset available on a year over year basis, and changes over time to reflect the growth rate of the site and the volume of lumber that can be recovered from logs. This method recognizes the fact that no revenues are generated at the onset of the project, and that the proponent would be without any revenue stream for thirteen to twenty-seven years. What this calculation does provide for is the fact that an offset producer could have a different customer every year as only the volume of credits generated are available for sale. On the other hand, the average method assumes that the carbon sequestered follows an "even flow", and that the offsets produced at a higher rate in later years are brought forward.

In both calculations, a twenty percent (20\%) withholding reserve pool was applied to the volume of offsets being generated. This reserve pool is necessary to meet the requirement for permanence, and act as "insurance" against potential future events that would result in carbon being emitted from the project (e.g., mortality or fire).

Table 6 shows that using the actual production calculations, only two out of sixteen scenarios show a positive rate of return, i.e. $0.38 \%$ and $0.27 \%$ respectively for scenario SI50-24 with MoFR cost base, and scenario SI5018 with Canfor cost base.

Using the average rate calculation, only one scenario, SI50-24 with MoFR cost base, shows a positive rate of return $(0.51 \%)$. It is important to note that these rates of return are over 57 - 110 year horizons.

\section{Conclusions}

Although accepted as a common mechanism for gener-

Table 5. Historic pricing information of $A / R$ projects [1,7].

\begin{tabular}{ccc}
\hline Year & Price (US\$) & Price (Cdn\$) \\
\hline 2006 & 6.8 & 7.21 \\
2007 & 9.85 & 10.44 \\
2008 & 5.89 & 6.24 \\
2009 & 6.34 & 6.72 \\
4 Years Average & $\mathbf{7 . 2 2}$ & $\mathbf{7 . 6 5}$ \\
\hline
\end{tabular}

ating carbon credits, the quality and quantity of the credits generated through forest projects could be somewhat risky because of the challenges posed in managing the quality-related issues of additionality [10], permanence [2], leakage, co-benefits, registration and reporting transparency as per standards, and in the selection and use of modeling instruments [1-3,7,10,16,18-21]. However, the various quality- and quantity-related challenges discussed in various studies have been taken care of while estimating the carbon credits and then keeping $20 \%$ of the carbon credits for various kinds of leakages and modeling issues. In fact, the estimation process used is conservative in nature.

Forest carbon projects, both afforestation and reforestation types, are widely held as an acceptable, if not preferred, project type for sequestering carbon and generating metric tonnes of carbon dioxide equivalent $\left(\mathrm{MtCO}_{2} \mathrm{e}\right)$ for the un-regulated market. This study looked at the production potential in both qualitative and quantitative terms of establishing such projects on private land, and it could be helpful to researchers and entrepreneurs who may intend to generate carbon credits on their private lands in central British Columbia, Canada.

From IRR point of view, of the sixteen scenarios modeled, only three scenarios generated positive IRR, ranging from $0.27 \%-0.51 \%$. These low rates of return indicate that these projects are not going to make enough money under the low prices of carbon credits, especially considering that the length of the projects varies from 57 110 years. On the other hand, project establishment costs are unlikely to decrease substantially, and site productivity, which is also a function of the land base, cannot be changed. Therefore, the only way to make these projects financially viable would be for the market pricing of the offsets to increase.

Overall, it can be concluded that forest carbon projects on private land in central British Columbia are not restricted by any qualitative and quantitative production criterion. However, these projects are found to be financially unviable under the current costing and offset pricing regimes on various biogeo sites in which a very large share of private lands fall.

Table 6. Internal Rate of Return (IRR) for Canfor and MoFR cost bases**.

\begin{tabular}{ccccc}
\hline $\begin{array}{c}\text { Zonal Site Index } \\
\text { (SI-50) }\end{array}$ & $\begin{array}{c}\text { IRR-Canfor Cost Base } \\
\text { with Actual Production } \\
\left(\mathbf{M t C O}_{\mathbf{2}} \mathbf{e}\right)\end{array}$ & $\begin{array}{c}\text { IRR-Canfor Cost Base } \\
\text { with Average Production } \\
\mathbf{( M t C O}_{\mathbf{2}} \mathbf{)}\end{array}$ & $\begin{array}{c}\text { IRR-MoFR Cost Base } \\
\text { with Actual Production } \\
\text { (MtCO} \mathbf{2})\end{array}$ & $\begin{array}{c}\text { IRR-Canfor Cost Base } \\
\text { with Average Production } \\
\text { (MtCO } \mathbf{e})\end{array}$ \\
\hline 24 & $-0.71 \%$ & $-0.90 \%$ & $0.38 \%$ & $0.51 \%$ \\
21 & -1.005 & $-1.88 \%$ & $-0.92 \%$ & $-0.64 \%$ \\
18 & $0.27 \%$ & $-1.08 \%$ & $-0.47 \%$ & $-0.07 \%$ \\
12 & -0.715 & $-1.54 \%$ & $-1.15 \%$ & $-0.94 \%$ \\
\hline
\end{tabular}

\footnotetext{
${ }^{* *}$ Assumption: $80 \%$ of the total production available for sale, and $\$ 7.65$ as the price/ $\mathrm{MtCO}_{2} \mathrm{e}$.
} 
This study was limited in scope and focused on zonal (average) site productivities of private land when modeling volumes of carbon offsets generated on individual sites. Moreover, average costs for crop establishment and historical average pricing were used in IRR calculations. The analysis was conservative in nature: it did not include volume of carbon offsets generated as a result of any additional biomass above the volume contributed by lumber, and it did not attribute a value to the $20 \%$ volume of credits withheld as required to assure permanence. Also, it did not value the residual fiber volume at culmination age.

In future research work, the production volume and pricing equations could be applied to specific site attributes to determine project viability for each specific private piece of land so as to generate more detailed information. Also, different prices of the carbon credits can be tested to find the minimum price that the market would need to support to make the carbon credit production on private lands viable. The study could also be replicated for other biogeoclimatic zones at the provincial, national, and international level.

\section{REFERENCES}

[1] K. Hamilton, M. Sjardin, T. Marcello and G. Xu, "Forging a Frontier: State of the Voluntary Carbon Markets 2008,” New Carbon Finance and Ecosystem Marketplace, New York, 2008.

[2] T. Rotherham, "Discussion of Various Policy and Technical Aspects of Forest Carbon Protocols and Forest Carbon Project Management,” Discussion Paper, Vol. 1, Canadian Federation of Woodlot Owners, Canada, 2009.

[3] M. Greig and G. Bull, "Carbon Management in British Columbia's Forests: Opportunities and Challenges,” Forrex Forum for Research and Extension in Natural Resources Society, Kamloops, 2009.

[4] T. Neeff and S. Henders, "Guidebook to Markets and Commercialization of Forestry CDM Projects,” Tropical Agricultural Research and Higher Education Center (CATIE), Turrialba, 2007.

[5] X. Niu and S. Duiker, "Carbon Sequestration Potential by Afforestation of Marginal Agricultural Land in the Midwestern US,” Forest Ecology and Management, Vol. 223, No. 1-3, 2006, pp. 415-427. doi:10.1016/j.foreco.2005.12.044

[6] Pacific Carbon Trust, "Pacific Carbon Trust Annual Service Plan Report 2008/9,” Pacific Carbon Trust, Victoria, 2009.

[7] K. Hamilton, R. Bayon, G. Turner and D. Higgins, "State of the Voluntary Carbon Market 2007: Picking up Steam,” Ecosystems Marketplace and New Carbon Finance, New York, 2007.

[8] L. Ashford, J. Calvert, T. Neeff, et al., "The Forest Carbon Offsetting Survey,” 2009.

http://www.greenbiz.com/research/report/2009/04/17/fore st-carbon-offsetting-survey-2009
[9] A. Kollmuss, M. Lazarus, C. Lee and C. Polycarp, “A Review of Offset Programs: Trading Systems, Funds, Protocols, Standards and Retailers," Stockholm Environment Institute, Stockholm, 2008.

[10] J. L. Beane, J. M. Hagan, A. A. Whitman and J. S. Gunn, "Forest Carbon Offsets: A Scorecard for Evaluating Project Quality,” Manomet Center for Conservation Sciences, Brunswick, 2008.

[11] M. Kim, B. A. McCarl and B. C. Murray, "Permanence Discounting for Land-Based Carbon Sequestration,” Ecological Economics, Vol. 64, No. 4, 2008, pp. 763-769. doi:10.1016/j.ecolecon.2007.04.013

[12] G. Marland, K. Fruit and R. Sedjo, “Accounting for Sequestering Carbon: The Question of Permanence," Environmental Science \& Policy, Vol. 4, No. 6, 2001, pp. 259268. doi:10.1016/S1462-9011(01)00038-7

[13] C. Palmer, M. Ohndorf and I. A. MacKenzie, "Life’s a Breach! Ensuring 'Permanence' in Forest Carbon Sinks Under Incomplete Contract Enforcement,” Institute for Environmental Decisions, Zurich, 2009.

[14] R. T. Watson, I. R. Nolin and B. Bolin, "Land Use, LandUse Change, and Forestry: A Special Report of the Intergovernmental Panel on Climate Change,” Cambridge University Press, Cambridge, 2000.

[15] A. Black, R. S. Jassal and A. L. Fredeen, "Carbon Sequestration in British Columbia's Forests and Management Options,” Pacific Institute for Climate Solutions, Victoria, 2008.

[16] W. A. Kurz, C. C. Dymond, T. M. White, G. Stinson, C. H. Shaw, G. J. Rampley, C. Smyth, et al., "CBM-CFS3: A Model of Carbon-Dynamics in Forestry and Land-Use Change Implementing IPCC Standards," Ecological Modeling, Vol. 220, No. 4, 2009, pp. 480-504. doi:10.1016/j.ecolmodel.2008.10.018

[17] K. J. Lewis, "Forestry and the Forest Industry in the Central Interior of British Columbia,” Western Geography, Vol. 12, 2002, pp. 185-215.

[18] B. Lim, S. Brown and B. Schlamadinger, "Carbon Accounting for Forest Harvesting and Wood Products: Review and Evaluation of Different Approaches," Environmental Science \& Policy, Vol. 2, No. 2, 1999, pp. $207-$ 216. doi:10.1016/S1462-9011(99)00031-3

[19] O. R. Masera, J. F. Garza-Caligaris, M. Kanninen, T. Karjalainen, J. Liski, G. J. Nabuurs, A. Pussinen, B. H. J. de Jong and G. M. J. Mohren, "Modeling Carbon Sequestration in Afforestation, Agroforestry and Forest Management Project: The C02FIX V.2 Approach,” Ecological Modeling, Vol. 164, No. 2-3, 2003, pp. 177-199. doi:10.1016/S0304-3800(02)00419-2

[20] B. Seely, C. Welham and H. Kimmins, "Carbon Sequestration in a Boreal Forest Ecosystem: Results from the Ecosystem Simulation Model, FORECAST," Forest Ecology and Management, Vol. 162, No. 1-2, 2002, pp. 123135. doi:10.1016/S0378-1127(02)00303-1

[21] R. N. Stavins and K. R. Richards, “The Cost of US Forest-Based Carbon Sequestration,” Pew Center on Global Climate Change, Arlington, 2005. 